\title{
Características de dossel e de rendimento em feijão-caupi ereto em diferentes densidades populacionais
}

\author{
Antônio Aécio de Carvalho Bezerra(1), Francisco José Alves Fernandes Távora ${ }^{(2)}$, \\ Francisco Rodrigues Freire Filho ${ }^{(3)}$ e Valdenir Queiroz Ribeiro ${ }^{(3)}$
}

(1)Universidade Federal do Piauí, BR 135, Km 03, Planalto Horizonte, CEP 64900-000 Bom Jesus, PI. E-mail: aecio@ufpi.br (2)Universidade Federal
do Ceará, Campus do Pici, Departamento de Fitotecnia, Caixa Postal 6.012, CEP 60451-970 Fortaleza, CE. E-mail: tavora@ufc.br (3)Embrapa
Meio-Norte, Avenida Duque de Caxias, no 5.650, CEP 64006-220 Teresina, PI. E-mail: freire@cpamn.embrapa.br, valdenir@cpamn.embrapa.br

Resumo - O objetivo deste trabalho foi avaliar os efeitos de diferentes densidades populacionais sobre as características morfológicas e de rendimento de grãos, numa linhagem moderna de feijão-caupi [Vigna unguiculata (L.) Walp.]. O experimento foi conduzido em 2002, em delineamento de blocos ao acaso, no esquema fatorial $3 \times 5$, com três espaçamentos entre fileiras $(0,4,0,5$ e $0,6 \mathrm{~m})$ e cinco populações de plantas $\left(10^{5}, 2 \times 10^{5}, 3 \times 10^{5}, 4 \times 10^{5}\right.$ e $5 \times 10^{5}$ plantas ha-1), com quatro repetições. Não houve interação significativa entre os fatores para nenhum dos caracteres. O número de nós no ramo principal, o número de grãos por vagem e o peso de 100 grãos não foram influenciados significativamente pelos espaçamentos entre linhas e populações de plantas. Aumentos na densidade populacional suscitaram reduções significativas no número de ramos laterais, no número de vagens por planta e na produção de grãos por planta. Houve acréscimo de $16,7 \%$ no rendimento de grãos da população de 100 mil em comparação ao de 500 mil plantas por hectare. Os diferentes arranjos de plantas promoveram modificações na morfologia, nos componentes de produção e no rendimento de grãos do feijão-caupi.

Termos para indexação: Vigna unguiculata, espaçamento entre linhas, estande, rendimento de grãos.

\section{Canopy and yield characteristics of a bunch-type cowpea under different population densities}

\begin{abstract}
The objective of this study was to evaluate the effects of different population densities on the morphologic characteristics and grain yield of a modern bunch-type cowpea line [Vigna unguiculata (L.) Walp.]. The experiment was carried out in 2002, in a randomized block design, with a factorial arrangement $3 \times 5$, with three between-row spacings $(0.4,0.5$ and $0.6 \mathrm{~m})$ with five plant populations $\left(10^{5}, 2 \times 10^{5}, 3 \times 10^{5}, 4 \times 10^{5}\right.$, and $5 \times 10^{5}$ plants $\mathrm{ha}^{-1}$ ), and four replicates. There were no significant interactions among the factors for any of the characters. The number of nodes in the main stem, number of seeds per pod, and the weight of 100 seeds were not significantly influenced by row spacing and plant populations. Increases in the population density caused significant reductions in the number of lateral branches, number of pods per plant, and grain yield per plant. There was an increase of $16,7 \%$ in grain yield from the population of 100 thousand to the 500 thousand plants per hectare. The different arrangements of cowpea plants promoted changes in the morphology, yield components, and grain yield.
\end{abstract}

Index terms: Vigna unguiculata, row spacing, stand, grain yield.

\section{Introdução}

No Brasil, o feijão-caupi, Vigna unguiculata (L.) Walp., tem significativa importância socioeconômica como suprimento alimentar, na fixação de mão de obra no campo e como componente da produção agrícola, especialmente nas regiões Norte e Nordeste (Bezerra et al., 2008; Rocha et al., 2009), onde apresenta, segundo o Instituto Brasileiro de Geografia e Estatística (2009), produtividade de 524 e $432 \mathrm{~kg} \mathrm{ha}^{-1}$, respectivamente.

Explorado tradicionalmente nos sistemas agrícolas familiares, em cultivo de sequeiro e com baixo nível tecnológico, o feijão-caupi tem sido pesquisado mais intensamente nas últimas décadas (Xavier et al., 2005). Isto tem contribuído para melhorar sua produtividade $\mathrm{e}$ rentabilidade que, com outros fatores, vêm despertando o interesse de médios e grandes produtores pela cultura (Freire Filho et al., 2005; Bezerra et al., 2008), principalmente na região dos Cerrados, para utilização em safrinha ou como cultura principal. Esses fatos têm gerado demanda por cultivares modernas que atendam às exigências de adensamento e de manejo dos sistemas tecnificados.

Pesq. agropec. bras., Brasília, v.44, n.10, p.1239-1245, out. 2009 
O porte da planta tem influência direta na resposta do feijão-caupi ao adensamento populacional, pois os decréscimos observados na produção de grãos por planta, em consequência do aumento da população de plantas por hectare, ocorrem em menor intensidade nos genótipos de porte ereto, que nos de porte enramador (Nangju et al., 1975; Cardoso et al., 1997).

A arquitetura da planta e o sistema de produção influenciam na determinação do arranjo de plantas mais adequado, para que os fatores de produção sejam eficientemente aproveitados e o potencial produtivo da cultivar maximizado (Bezerra, 2005).

A densidade e o arranjo de plantas irão determinar o grau de competição e o estádio em que ela será mais intensa entre as plantas. Segundo Bezerra et al. (2008), a competição em intensidade elevada, nos estádios iniciais do desenvolvimento da cultura, pode favorecer o surgimento de plantas improdutivas, causar a diminuição do estande produtivo final e, consequentemente, o rendimento de grãos.

A maior expressão do potencial produtivo das cultivares é resultado da combinação de um conjunto de fatores, dos quais se destaca a população de plantas, por ter influência marcante em várias características morfofisiológicas e de rendimento de grãos (Bezerra, 2005). Segundo Cardoso et al. (2005), a escassez ou excesso de plantas por área é uma das causas da baixa produtividade do feijão-caupi no Brasil.

Para qualquer cultura, o conhecimento da combinação ótima do espaçamento entre fileiras e da densidade de plantas é essencial para a maximização econômica da produção (Henderson et al., 2000). Entretanto, o melhor arranjo de plantas depende das características intrínsecas da cultivar, como porte, hábito de crescimento e arquitetura de planta, bem como, do sistema de manejo da cultura.

Nos sistemas tradicionais, e principalmente nos tecnificados, são essenciais os conhecimentos sobre as alterações morfofisiológicas e as modificações nos componentes de produção e no rendimento de grãos das cultivares modernas, quando submetidas a diferentes densidades populacionais.

O objetivo deste trabalho foi avaliar os efeitos de diferentes densidades populacionais sobre as características morfológicas, componentes de produção e rendimento de grãos de uma linhagem moderna de feijão-caupi.

\section{Material e Métodos}

O ensaio foi instalado no dia 20 de agosto de 2002, em área experimental da Embrapa Meio-Norte, em Teresina, PI, a $5^{\circ} 5^{\prime} \mathrm{S}, 42^{\circ} 48^{\prime} \mathrm{W}$ e $72 \mathrm{~m}$ de altitude, em sistema irrigado por aspersão. O solo do tipo Neossolo Flúvico apresentou composição granulométrica média de $48 \mathrm{~g} \mathrm{~kg}^{-1}$ de areia grossa, $684 \mathrm{~g} \mathrm{~kg}^{-1} \mathrm{de}$ areia fina, $55 \mathrm{~g} \mathrm{~kg}^{-1}$ de silte e $213 \mathrm{~g} \mathrm{~kg}^{-1}$ de argila, e os seguintes atributos químicos na camada de 0-20 cm de profundidade: $\mathrm{pH} 5,9 ; \mathrm{MO}, 21 \mathrm{~g} \mathrm{~kg}^{-1}$; $\mathrm{P}, 48 \mathrm{mg} \mathrm{dm}^{-3} ; \mathrm{K}, 6,9 \mathrm{mmol}_{\mathrm{c}} \mathrm{dm}^{-3} ; \mathrm{Ca}, 24 \mathrm{mmol}_{\mathrm{c}} \mathrm{dm}^{-3}$; $\mathrm{Mg}, 11 \mathrm{mmol}_{\mathrm{c}} \mathrm{dm}^{-3} ; \mathrm{Al}, 0 \mathrm{mmol}_{\mathrm{c}} \mathrm{dm}^{-3} ; \mathrm{H}+\mathrm{Al}, 19 \mathrm{mmol}_{\mathrm{c}}$ $\mathrm{dm}^{-3}$; CTC $60,9 \mathrm{mmol}_{\mathrm{c}} \mathrm{dm}^{-3}$; e saturação por bases de $68,8 \%$. Com base no resultado da análise de solo, optouse por não fazer a adubação da área experimental com fertilizantes. A área experimental foi preparada com uma aração e duas gradagens cruzadas e foi irrigada com uma lâmina d'agua de $40 \mathrm{~mm}$, nos dois dias que antecederam ao plantio.

A linhagem IT87D-611-3 de feijão-caupi, proveniente do International Institute of Tropical Agriculture, foi selecionada por apresentar porte ereto, hábito de crescimento determinado e arquitetura de plantas considerada propícia para a colheita mecanizada. Foram avaliados três espaçamentos entre fileiras $(0,4,0,5 \mathrm{e}$ $0,6 \mathrm{~m})$ e cinco populações de plantas por hectare $\left(1 \times 10^{5}\right.$, $2 \times 10^{5}, 3 \times 10^{5}, 4 \times 10^{5}$ e $5 \times 10^{5}$ plantas ha ${ }^{-1}$ ), no esquema fatorial $3 \times 5$, tendo-se utilizado o delineamento de blocos completos ao acaso, com quatro repetições. Para os espaçamentos entre fileiras de 0,6 e $0,5 \mathrm{~m}$, as parcelas foram constituídas por quatro fileiras, com área total de $13,2 \mathrm{~m}^{2}$ e $11 \mathrm{~m}^{2}$, respectivamente. Para o espaçamento entre fileiras de $0,4 \mathrm{~m}$, as parcelas foram constituídas por cinco fileiras, com área total de $11 \mathrm{~m}^{2}$. A área útil para todas as parcelas foi de $5 \mathrm{~m}^{2}$. O espaçamento entre plantas, dentro da fileira, e o número de plantas por metro estão apresentados na Tabela 1 .

A semeadura foi realizada manualmente, em sulcos de $0,05 \mathrm{~m}$ de profundidade, tendo-se utilizado barbantes pré-marcados, com base no espaçamento entre plantas dentro da fileira de cada população; foram distribuídas duas sementes por cova, com o objetivo de se assegurar o estande inicial pré-estabelecido. O desbaste foi realizado 15 dias após o plantio, tendo-se deixado apenas uma planta por cova. Nesta operação, as plantas excedentes foram cortadas abaixo do nó cotiledonar rente à superfície do solo, para evitar o rebrotamento, 
bem como a danificação do sistema radicular das plantas remanescentes.

Para o controle das plantas daninhas, foram realizadas: uma aplicação em pré-plantio de S-metalocloro (Dual Gold), na dosagem de $1.440 \mathrm{~g} \mathrm{ha}^{-1}$ i.a.; e uma capina com cultivador à tração animal com complementação manual.

No controle fitossanitário do ensaio, foi efetuada uma pulverização preventiva com metalaxyl+mancozeb (Ridomil Mancozeb BR), na dosagem de $30 \mathrm{~g} \mathrm{ha}^{-1}$ i.a., para controle de fungos do solo, e duas pulverizações curativas, à base de thiamethoxan (Actara), na concentração de $3,75 \mathrm{~g} \mathrm{~L}^{-1}$ i.a., para o controle de cigarrinhas (Empoasca kraemeri Ross \& Moore), pulgões (Apis cracyvora Koch) e mosca-branca (Bemisia tabaci Genn).

Foram avaliados, aos 70 dias após o plantio, os seguintes caracteres: número de nós no ramo principal (NNRP); número de ramos laterais (NRL); número de vagens por planta (NVP); número de grãos por vagem (NGV); peso de 100 grãos (PCG); produção de grãos por planta (PGP); e rendimento de grãos (REND). O NNRP corresponde à contagem direta dos nós, a partir do nó cotiledonar ao último nó do ramo principal; o NRL refere-se ao número de ramos laterais, no ramo principal; o NGV é o número médio de grãos de cinco vagens escolhidas ao acaso; o PCG, em gramas, corresponde ao peso médio de três amostras de 100 grãos com 13\% de umidade; o PGP, em gramas, representa a produção total de grãos da planta; o REND é a produção de grãos na área útil da parcela, transformada para quilogramas por hectare.

Os dados referentes aos caracteres NNRP, NRL, NVP e PGP correspondem à média de três plantas individuais escolhidas ao acaso.

Os dados foram analisados estatisticamente, por meio da análise de variância com regressão polinomial, pelo SAS (SAS Institute, 2000).

\section{Resultados e Discussão}

Os caracteres NNRP, NGV e PCG não diferiram significativamente em relação a espaçamento e a população de plantas. O NRL apresentou significâncias estatísticas pelo teste $\mathrm{F}$ quanto ao espaçamento entre fileiras e, juntamente com o NVP, PGP e REND, quanto à população de plantas, o que concorda com os resultados obtidos por Cardoso \& Ribeiro (2006). Porém, não houve interação significativa entre o espaçamento e a população de plantas, para nenhum dos caracteres avaliados (Tabela 2).

$\mathrm{A}$ análise de regressão revelou valores de $\mathrm{F}$ não significativos para o NNRP, NGV e PCG, em relação à população de plantas e ao espaçamento entre fileiras, o que indica que os diferentes arranjos de plantas adotados não influenciaram significativamente $o$ NNRP, NGV e PCG. Resultados semelhantes para

Tabela 1. Número de plantas por metro de acordo com o espaçamento (m) entre fileiras e entre plantas dentro da fileira (EDF), em feijão-caupi.

\begin{tabular}{|c|c|c|c|c|c|c|}
\hline \multirow[t]{2}{*}{ População de plantas ha-1 } & \multicolumn{2}{|c|}{$0,4(\mathrm{~m})$} & \multicolumn{2}{|c|}{$0,5(\mathrm{~m})$} & \multicolumn{2}{|c|}{$0,6(\mathrm{~m})$} \\
\hline & $\mathrm{EDF}(\mathrm{m})$ & plantas $\mathrm{m}^{-1}$ & $\mathrm{EDF}(\mathrm{m})$ & plantas $\mathrm{m}^{-1}$ & $\mathrm{EDF}(\mathrm{m})$ & plantas $\mathrm{m}^{-1}$ \\
\hline 100.000 & 0,250 & 4 & 0,200 & 5 & 0,166 & 6 \\
\hline 200.000 & 0,125 & 8 & 0,100 & 10 & 0,083 & 12 \\
\hline 300.000 & 0,083 & 12 & 0,066 & 15 & 0,055 & 18 \\
\hline 400.000 & 0,062 & 16 & 0,050 & 20 & 0,041 & 24 \\
\hline 500.000 & 0,050 & 20 & 0,040 & 25 & 0,033 & 30 \\
\hline
\end{tabular}

Tabela 2. Análises de variância, médias gerais e coeficientes de variação, para o número de nós no ramo principal (NNRP), número de ramos laterais (NRL), número de vagens por planta (NVP), número de grãos por vagem (NGV), peso de 100 grãos (PCG), produção de grãos por planta (PGP) e rendimento de grãos (REND), em feijão-caupi, linhagem IT87D-611-3.

\begin{tabular}{|c|c|c|c|c|c|c|c|c|}
\hline \multirow[t]{2}{*}{ Causas deVariação } & \multirow[t]{2}{*}{ GL } & \multicolumn{7}{|c|}{ Quadrados Médios } \\
\hline & & NNRP & NRL & NVP & NGV & PCG & PGP & REND \\
\hline Bloco & 3 & 0,56 & 3,59 & 6,700 & 5,57 & 3,82 & 54,74 & $60.351,10$ \\
\hline Espaçamento (E) & 2 & $0,09^{\text {ns }}$ & $3,46 * *$ & $8,840^{\mathrm{ns}}$ & $3,42^{\text {ns }}$ & $1,54^{\mathrm{ns}}$ & $45,38^{\mathrm{ns}}$ & $76.525,20_{*}^{\mathrm{ns}}$ \\
\hline População (P) & 4 & $0,37^{\text {ns }}$ & $36,40 * *$ & $458,98 * *$ & $0,23^{\mathrm{ns}}$ & $1,75^{\mathrm{ns}}$ & $1.056,30 * *$ & $121.504,20^{*}$ \\
\hline$E \times P$ & 8 & $0,46^{\mathrm{ns}}$ & $0,94^{\mathrm{ns}}$ & $4,05^{\mathrm{ns}}$ & $1,96^{\mathrm{ns}}$ & $1,82^{\mathrm{ns}}$ & $7,44^{\mathrm{ns}}$ & $23.469,90^{\mathrm{ns}}$ \\
\hline Resíduo & 42 & 0,35 & 0,49 & 4,45 & 1,25 & 2,12 & 22,30 & $36.007,90$ \\
\hline Médias & - & 14,61 & 2,30 & 11,09 & 11,17 & 3,97 & 17,21 & $1.616,60$ \\
\hline $\mathrm{CV}(\%)$ & - & 4,07 & 30,30 & 19,00 & 10,00 & 10,40 & 27,40 & 11,70 \\
\hline
\end{tabular}

ns Não significativo. * e **Significativo a $5 \%$ e $1 \%$ de probabilidade, respectivamente, pelo teste $\mathrm{F}$. 
NGV e PCG foram obtidos por Távora et al. (2000) e Cardoso \& Ribeiro (2006).

O NRL apresentou valores de F significativos, com efeitos quadráticos para população de plantas e linear para espaçamento entre fileiras, o que indica que para ambos os fatores, ao se aumentar os níveis dentro dos intervalos estudados, diminui-se o número de ramos laterais por planta (Figura 1). Bezerra et al. (2001) avaliaram as relações causais entre o rendimento de grãos e seus componentes e obtiveram efeito direto negativo do NRL sobre o REND.

Oaumento na população de 100 mil para 500 mil plantas por hectare provocou redução de $84,5 \%$ no número de ramos laterais. Com relação ao espaçamento entre plantas, a redução provocada pelo incremento no espaçamento de 0,4 para $0,6 \mathrm{~m}$ foi de $29,9 \%$. Nas maiores populações, a competição intraespecífica mais intensa no dossel pode ter potencializado a dominância apical, em detrimento do desenvolvimento das ramificações laterais. Távora et al. (2001) observaram maior número de ramos laterais para o espaçamento entre fileiras de $0,4 \mathrm{~m}$, em comparação
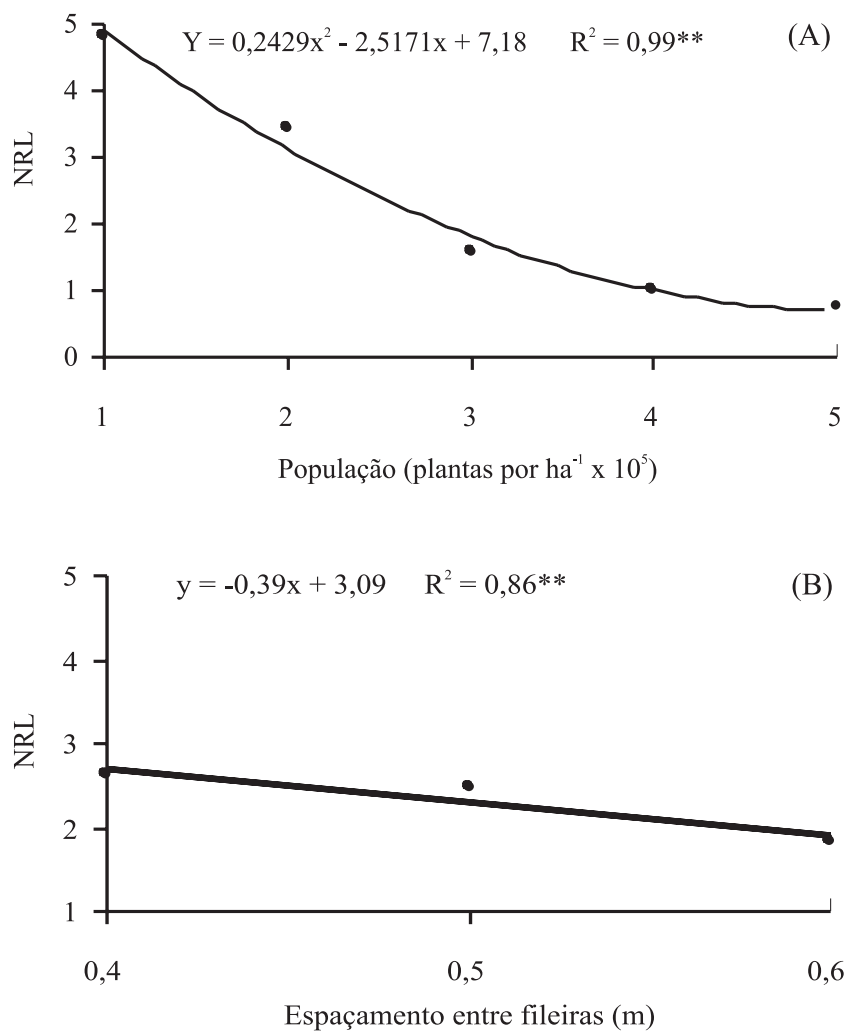

Figura 1. Número de ramos laterais (NRL) em feijão-caupi, linhagem IT87D-611-3, em função da população de plantas por hectare (A) e do espaçamento entre fileiras (B). ao de $0,8 \mathrm{~m}$. Segundo os autores, a distribuição mais equidistante das plantas, nos espaçamento de $0,4 \mathrm{~m}$, reduziu a competição entre plantas pelos fatores de produção e proporcionou maior número de ramos laterais por planta.

A redução do NRL implica em diminuição na área foliar da planta, notadamente nas populações mais adensadas, o que segundo Saidi et al. (2007) afeta significativamente a produção e partição de biomassa, o peso dos nódulos radiculares e a produção de grãos da cultura.

O NRLe suas características influenciam diretamente a arquitetura da planta e o potencial de rendimento de grãos e, conforme observado por Brathwaite (1982), Santos \& Araujo (2000) e Mendes et al. (2005), o NRL diminui significativamente com o aumento da população de plantas.

A população de plantas apresentou efeito quadrático significativo sobre o NVP, enquanto o efeito do espaçamento entre fileiras, sobre o mesmo caráter, foi não significativo. $\mathrm{O}$ aumento $\mathrm{da}$ densidade populacional de 100 mil para 300 mil plantas ha-1 e de 100 mil para 500 mil plantas ha ${ }^{-1}$ reduziu o NVP em 63 e 69\%, respectivamente. Entretanto, para o intervalo de 300 mil a 500 mil plantas ha $^{-1}$, a redução verificada foi de 16,2\% (Figura 2). Távora et al. (2000) enfatizaram que o aumento na densidade de plantas reduz significativamente o NVP e, conforme Brathwaite (1982), o NVP é o componente de produção mais afetado pelo aumento na densidade de plantas.

O aumento da competição suscitado nas populações mais adensadas teve efeitos diretos na capacidade

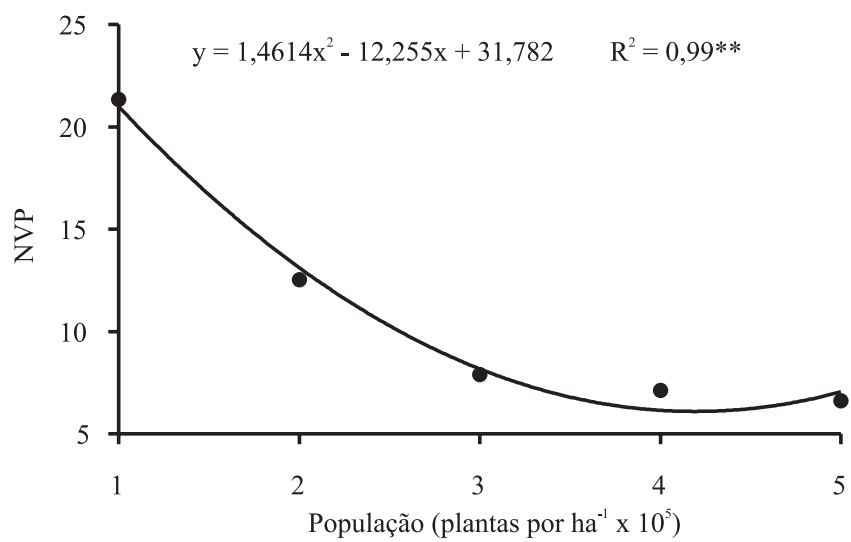

Figura 2. Variação média no número de vagens por planta (NVP) em feijão-caupi, linhagem IT87D-611-3, em função da população de plantas por hectare. 
produtiva da planta, com diminuição de $69 \%$ no número de vagens por planta, e indireto, com a redução de $84,5 \%$ no número de ramos laterais, em comparação à menor e à maior população. Isso demonstra que a maior proporção da redução no NVP ocorreu em função da diminuição no NRL. Carvalho et al. (2000) e Mendes et al. (2005) relataram que, nas altas populações, há efeito direto na capacidade produtiva da planta com a diminuição do número de inflorescências e de flores por planta.

Para a PGP, houve efeitos significativos quadráticos para a população de plantas e linear para o espaçamento entre fileiras (Figura 3). Quando as populações foram aumentadas de 100 mil para 300 mil plantas ha ${ }^{-1}$ e de 300 mil para 500 mil plantas ha ${ }^{-1}$, a PGP decresceu em 60,8 e 15,9\%, respectivamente. Comparando-se as populações de 100 mil e 500 mil plantas ha-1, a redução na PGP foi de $67,1 \%$. Houve, também, redução de $16 \%$ na PGP, quando o espaçamento entre fileiras foi aumentado de 0,4 para $0,6 \mathrm{~m}$ e, entre dois níveis consecutivos, a redução na PGP foi de $8 \%$.
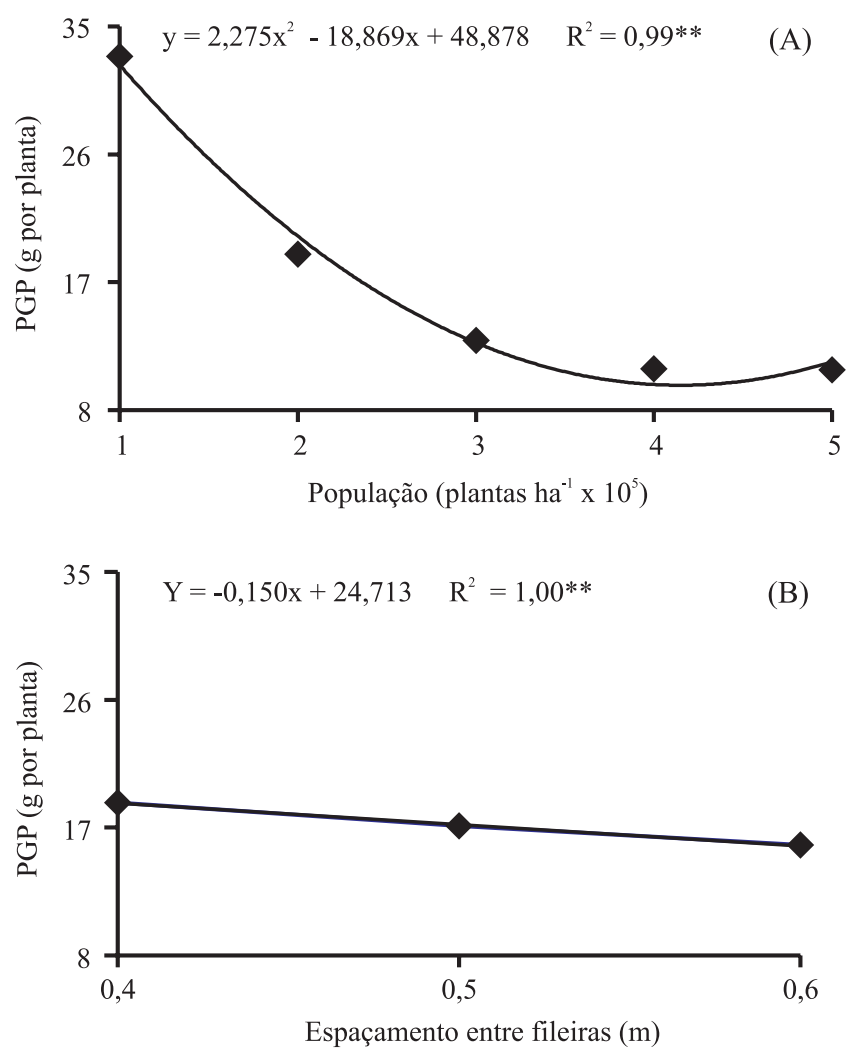

Figura 3. Produção de grãos por planta (PGP) em feijão-caupi, linhagem IT87D-611-3, em função da população de plantas por hectare (A) e do espaçamento entre fileiras (B).
Para o espaçamento entre fileiras de $0,4 \mathrm{~m}$, além da maior produção de grãos por planta, observaram-se também os maiores valores para o número de vagens por planta, o que indica que os arranjos populacionais mais equidistantes favoreceram melhor expressão do potencial produtivo da planta.

A intensidade de redução na PGP, entre dois níveis populacionais consecutivos, diminuiu à proporção que os níveis populacionais aumentaram. Para os dois intervalos entre as populações de 100 mil, 200 mil e 300 mil plantas ha $^{-1}$, as reduções na PGP foram de 42,4 e $32 \%$, respectivamente, enquanto para os intervalos entre as populações de $300 \mathrm{mil}, 400 \mathrm{mil} \mathrm{e}$ 500 plantas ha $^{-1}$, as reduções foram de 15,5 e $0,46 \%$, respectivamente. Esses dados evidenciam a capacidade adaptativa da linhagem, bem como a tendência para a estabilização da capacidade produtiva mínima da planta, entre as populações de $400 \mathrm{mil}$ a $500 \mathrm{mil}$ plantas $\mathrm{ha}^{-1}$. Decréscimos na PGP, em resposta ao adensamento, foram obtidos por Mendes et al. (2005), Morgado (2006) e Bezerra et al. (2008).

Com base na equação de regressão, para os níveis estudados, aumentando-se a população de plantas por hectare, aumenta-se também o REND (Figura 4); o acréscimo obtido com o aumento da população de plantas de 100 mil para 500 mil plantas ha-1 foi de $16,7 \%$, que representa incremento de $243,8 \mathrm{~kg} \mathrm{ha}^{-1}$ no rendimento de grãos.

O rendimento máximo estimado de $1.699,5 \mathrm{~kg} \mathrm{ha}^{-1}$ seria obtido para uma população aproximada de 490 mil plantas por hectare. Portanto, bem próximo da maior população de plantas estudada, o que indica

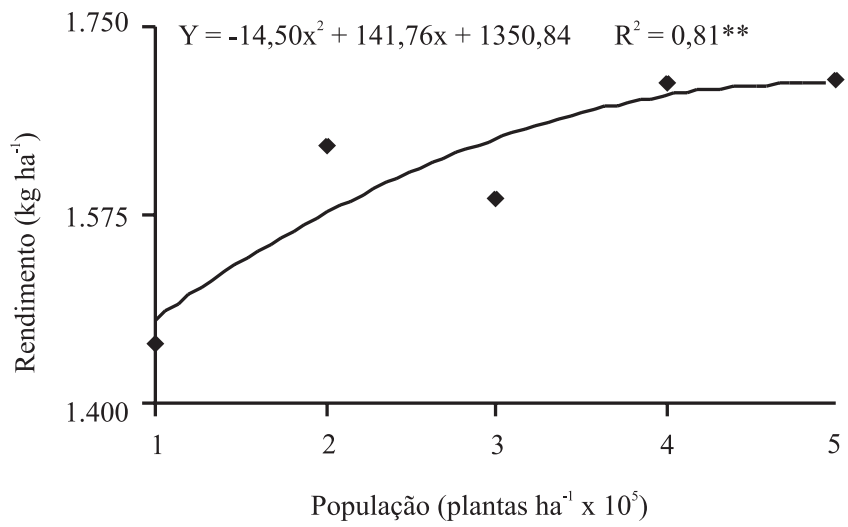

Figura 4. Rendimento de grãos em feijão-caupi, linhagem IT87D-611-3, na média dos três espaçamentos entre fileiras e em função da população de plantas por hectare. 
que apesar das reduções observadas, em resposta ao aumento da população de plantas por hectare, para a variável NRL e para os componentes de produção NVP e PGP, elas provavelmente foram suplantadas pelos acréscimos advindos do aumento no número de plantas por hectare. Com esses resultados demonstra-se a grande capacidade da linhagem em manter um alto potencial de produção de grãos, quando submetida a diferentes níveis de competição intraespecífica.

A população de plantas por área tem grande importância no rendimento de grãos da cultura, e seus efeitos podem variar com o porte, notadamente quando plantas de porte ereto e semiereto são usadas. Santos \& Araujo (2000) observaram que genótipos semieretos apresentam os maiores rendimentos, quando cultivados em grandes densidades populacionais. Em estudos com cinco linhagens modernas de porte ereto, Bezerra et al. (2008) obtiveram, para a população de 300 mil plantas ha-1, o rendimento médio de $1.836 \mathrm{~kg} \mathrm{ha}^{-1}$, que foi $13,2 \%$ maior do que o rendimento médio na população de 100 mil plantas ha ${ }^{-1}$.

\section{Conclusões}

1. O número de nós no ramo principal, o número de grãos por vagem e o peso de 100 grãos não são influenciados pelos diferentes arranjos de plantas de feijão-caupi.

2. O incremento na densidade de plantas de feijão-caupi promove reduções significativas no número de vagens por planta e na produção de grãos por planta, porém promove acréscimo na produtividade de grãos.

3. Os diferentes arranjos de plantas de feijão-caupi promovem modificações na morfologia, nos componentes de produção e no rendimento de grãos.

\section{Agradecimentos}

À Coordenação de Aperfeiçoamento de Pessoal de Nível Superior, por bolsa concedida; e à Embrapa Meio-Norte, pelo apoio na condução do experimento.

\section{Referências}

BEZERRA, A.A. de C. Efeitos de arranjos populacionais na morfologia e produtividade de feijão-caupi de crescimento determinado e porte ereto. 2005. 123p. Tese (Doutorado) Universidade Federal do Ceará, Fortaleza.

BEZERRA, A.A. de C.; ANUNCIAÇÃO FILHO, C.J. da; FREIRE FILHO, F.R.; RIBEIRO, V.Q. Inter-relação entre caracteres de caupi de porte ereto e crescimento determinado. Pesquisa Agropecuária Brasileira, v.36, p.137-142, 2001.

BEZERRA, A.A. de C.; TÁVORA, F.J.A.F.; FREIRE FILHO, F.R.; RIBEIRO, V.Q. Morfologia e produção de grãos em linhagens modernas de feijão-caupi submetidas a diferentes densidades populacionais. Revista de Biologia e Ciências da Terra, v.8, p.85-93, 2008.

BRATHWAITE, R.A.I. Bodie bean responses to changes in plant density. Agronomy Journal, v.74, p.593-596, 1982.

CARDOSO, M.J.; MELO, F. de B.; ANDRADE JÚNIOR, A.S. de. Densidade de plantas de caupi em regime irrigado. Pesquisa Agropecuária Brasileira, v.32, p.399-405, 1997.

CARDOSO, M.J.; MELO, F. de B.; LIMA, M.G. de. Ecofisiologia e manejo de plantio. In: FREIRE FILHO, F.R.; LIMA, J.A. de A.; RIBEIRO, V.Q. (Ed.). Feijão-caupi: avanços tecnológicos. Brasília: Embrapa Informação Tecnológica, 2005. p.212-228.

CARDOSO, M.J.; RIBEIRO, V.Q. Desempenho agronômico do feijão-caupi, cv. Rouxinol, em função de espaçamentos entre linhas e densidades de plantas sob regime de sequeiro. Ciência Agronômica, v.37, p.102-105, 2006.

CARVALHO, W.P. de; TÁVORA, F.J.A.F.; PINHO, J.L.N. de; PITOMBEIRA, J.B. Densidade de plantio na cultura do feijão-de-corda irrigada. I. Área foliar, interceptação da luz e características de florescimento. Ciência Agronômica, v.31, p.11-19, 2000.

FREIRE FILHO, F.R.; RIBEIRO, V.Q.; ALCÂNTARA, J. dos P.; BELARMINO FILHO, J.; ROCHA, M. de M. BRS Marataoã: nova cultivar de feijão-caupi com grão tipo sempre-verde. Revista Ceres, v.52, p.771-777, 2005.

HENDERSON, T.L.; JOHNSON, B.L.; SCHNEITER, A.A. Row spacing, plant population, and cultivar effects on grain amaranth in the northern Great Plains. Agronomy Journal, v.92, p.329-336, 2000 .

INSTITUTO BRASILEIRO DE GEOGRAFIA E ESTATÍSTICA. Censo agropecuário 2006. Rio de Janeiro: IBGE, 2009. 777p.

MENDES, R.M. de S.; TÁVORA, F.J.A.F.; PINHO, J.L.N. de; PITOMBEIRA, J.B. Alterações na relação fonte-dreno em feijão-de-corda submetido a diferentes densidades de plantas. Revista Ciência Agronômica, v.36, p.82-90, 2005.

MORGADO, L.B. Estudo sobre densidade de plantio de sorgo e feijão-caupi consorciados no Semi-Árido brasileiro. Revista Ciência Agronômica, v.37, p.357-363, 2006.

NANGJU, D.; LITTLE, T.M.; ANJORIN-OHU, A. Effect of plant density and spatial arrangement on seed yield of cowpea (Vigna-unguiculata (L.) Walp.). Journal of the American Society for Horticultural Science, v.100, p.467-470, 1975.

ROCHA, M. de M.; CARVALHO, K.J.M. de; FREIRE FILHO, F.R.; LOPES, A.C. de A.; GOMES, R.L.F.; SOUSA, I. da S. 
Controle genético do comprimento do pedúnculo em feijão-caupi. Pesquisa Agropecuária Brasileira, v.44, p.270-275, 2009.

SAIDI, M.; NGOUAJIO, M.; ITULYA, F.M.; EHLERS, J. Leaf harvesting initiation time and frequency affect biomass partitioning and yield of cowpea. Crop Science, v.47, p.1159-1166, 2007.

SANTOS, C.A.F.; ARAUJO, F.P. de. Produtividade e morfologia de genótipos de caupi em diferentes densidades populacionais nos sistemas irrigado e de sequeiro. Pesquisa Agropecuária Brasileira, v.35, p.1977-1984, 2000.

SAS INSTITUTE. SAS: user's guide. Version 8.0. Cary: SAS INSTITUTE, 2000.
TÁVORA, F.J.A.F.; CARVALHO, W.P. de.; PINHO, J.L.N. de; PITOMBEIRA, J.B. Densidade de plantio na cultura do feijão-de-corda irrigada. II. Componentes de produção e rendimento de grãos. Ciência Agronômica, v.31, p.20-26, 2000.

TÁVORA, F.J.A.F.; NOGUEIRA, S.L.; PINHO, J.L.N. de. Arranjo e população de plantas em cultivares de feijão-de-corda com diferentes características de copa. Ciência Agronômica, v.32, p.69-77, 2001.

XAVIER, G.R.; MARTINS, L.M.V.; RUMJANEK, N.G.; FREIRE FILHO, F.R. Variabilidade genética em acessos de caupi analisada por meio de marcadores RAPD. Pesquisa Agropecuária Brasileira, v.40, p.353-359, 2005.

Recebido em 15 de outubro de 2008 e aprovado em 27 de setembro de 2009 